\title{
The Feasibility of Fundal Retraction of the Gallbladder in the Single Port Laparoscopic Cholecystectomy: Comparison between a 4-instrument Fundal Retraction Group and a 3-instrument Group
}

Jung Sik Kim, M.D. ', Hyung Joon Han, M.D. ${ }^{1}$, Tae-Jin Song, M.D. ${ }^{1}$, Sae Byeol Choi, M.D. ${ }^{2}$, Wan-Bae Kim, M.D. ${ }^{2}$, Sang-Yong Choi, M.D. ${ }^{2}$, Sung-Ock Suh, M.D. ${ }^{3}$

Division of Hepatobiliopancreas and Transplantation Surgery, Department of Surgery, 'Korea University Ansan Hospital, Ansan,

${ }^{2}$ Korea University Guro Hospital, ${ }^{3}$ Korea University Anam Hospital, Seoul, Korea

Purpose: Owing to the accumulation of surgical experience, the indications of single port laparoscopic cholecystectomy (SLC) have increased. To overcome the difficulties and limitations of SLC, we included an additional instrument for use in retracting the gallbladder fundus. The aim of this study was to investigate the feasibility of 4-instrument fundal retraction SLC.

Methods: We retrospectively analyzed 134 patients who had undergone SLC for benign gallbladder disease. We compared the clinical outcome between patients who had undergone SLC without fundal retraction (3-instrument SLC, n=102) and those who had undergone SLC with fundal retraction (4-instrument fundal retraction SLC, $\mathrm{n}=32$ ).

Results: Of 134 patients, 47 were male and 87 were female. A significantly higher proportion of patients in the 4-instrument fundal retraction group had gallbladder distention and wall thickening than patients in the 3-instrument SLC group. No statistically significant difference in the incidence of pericholecystic inflammation, adhesion, and gallbladder perforation; duration of operation, the incidence of complications, and duration of postoperative hospital stay was observed between the two groups. In univariate analysis to perform 4-instrument fundal retraction SLC, higher BMI, the presence of gallbladder distension, and wall thickening were significant factors. In multivariate analysis, gallbladder distention and the presence of concurrent operation during SLC were independently significant factors for performing 4-instrument fundal retraction SLC.

Conclusion: Four-instrument fundal retraction SLC is a feasible and safe surgical procedure, particularly in patients with a high BMI, gallbladder distention, wall thickening, inflammation, or adhesions. If difficulties are encountered during 3-instrument SLC, simple fundal retraction using an additional instrument may be the preferred option prior to converting the operation to conventional laparoscopic cholecystectomy.

Keywords: Gallbladder/surgery; Cholecystectomy, Laparoscopic/methods; Cholecystitis, Acute/surgery; Inflammation/surgery

This is an Open Access article distributed under the terms of the Creative Commons Attribution Non-Commercial License (http:// creativecommons.org/licenses/by-nc/3.0/) which permits unrestricted non-commercial use, distribution, and reproduction in any medium, provided the original work is properly cited.
Received September 5, 2014

Revised 1st September 30, 2014

2nd October 8, 2014

3rd October 16, 2014

4th October 22, 2014

5th October 23, 2014

6th October 28, 2014

Accepted October 28, 2014

\section{Corresponding author}

Hyung Joon Han

Division of Hepatobiliopancreas and Transplantation, Department of Surgery, Korea University

Ansan Hospital, 123 Jeokgeum-ro,

Danwon-gu, Ansan 425-707, Korea

Tel: +82-31-412-4826

Fax: +82-31-412-4829

E-mail: hjhankorea@gmail.com

Copyright (๑) 2015 The Journal of Minimally Invasive Surgery. All rights reserved. 


\section{INTRODUCTION}

Single port laparoscopic cholecystectomy (SLC) has made substantial advances in minimally invasive surgery, with relevant prospective randomized controlled studies have been reported. ${ }^{1-5}$ However, a consensus has not been reached regarding the advantages and feasibility of this procedure. Several investigators have predicted that SLC will challenge conventional laparoscopic cholecystectomy (CLC) as the gold standard, ${ }^{2,56}$ while others have shown that SLC requires longer operative times, as well as involves increased surgical difficulty. ${ }^{1,4,7}$ Despite this controversy, SLC technique has minimized both complications and surgical costs; however, rapid implementation of such novel and under-researched techniques could lead to unexpectedly poor outcomes. ${ }^{8}$

A single port procedure involves using multiple straight and articulating laparoscopic instruments, combined with a surgical telescope, in a single incision. This procedure carries inherent limitations that include both a steeper learning curve and limited surgical indications. The parallel locations of the telescope and laparoscopic instruments within a single port make fine mechanical manipulations more difficult and timeconsuming than that in conventional laparoscopic surgery. Perhaps the greatest challenge in single port laparoscopy is that movemen tis limited to a forward-to-backward motion and there exists a potential for incomplete retraction. These challenges may compromise the safety of the procedure. Typically, SLC is performed with a 3-instrument technique.,5,8 Owing to the accumulation of surgical experience, the potential indications of SLC have been increased. In difficult cases, independent retraction of the gallbladder fundus is important to expose critical structures in Calot's triangle in order to achieve an optimally safety view. ${ }^{9}$

During the early period of SLC, our center utilized a 3-instrument technique (similar to the 3-port technique in the CLC). However, to ensure a safe operation, previous outcomes dictated the need for an additional instrument to retract the gallbladder fundus. We compared clinical outcomes and intraoperative findings between patients who underwent the 3-instrument SLC and those who underwent 4-instrument fundal retraction SLC.

\section{MATERIALS AND METHODS}

\section{Patients}

We retrospectively analyzed data from 134 patients who had undergone SLC for symptomatic gallstones or gallbladder polyps at the Department of Surgery, Korea University Ansan Hospital, from March 1, 2010 to February 28, 2011. Informed consent was obtained from all participants. Patients with a history of upper abdominal surgery, or suspected malignancy on the imaging studies were excluded from the groups. During this study, the 3-instrument technique was predominantly used to perform SLC. To achieve a safety view of Calot's triangle, an additional instrument was required for simple fundal retraction (depending on the preoperative or intraoperative findings). We compared the clinical characteristics between the patients who had undergone 3-instrument SLC ( $\mathrm{n}=102)$ and those who had undergone 4-instrument fundal retraction SLC $(n=32)$. Patient age, gender, operation time, past operation history, co-morbidity, body mass index (BMI), complications, histologic examinations, length of hospital stay, and intraoperative findings were compared between groups.

\section{Operation}

A single surgeon performed all SLC according to the directions by Han et al. ${ }^{8}$ Patients were placed in the supine position under general endotracheal anesthesia. Patients were placed right side up in the reverse Trendelenburg position. The surgeon stood on the left side of the patients along with the first assistant, and the monitor was placed on the patient's cranial side. We used ahandmade glove port or Glove port (Nelis, Bucheon, Republic of Korea). A single port was introduced through a 15- $\mathrm{mm}$ transumbilical vertical incision. The tips of four fingers of a No. 8 surgical glove were removed and a $12-\mathrm{mm}$ trocar and two 5-mm trocars were placed into the glove's respective fingers and then were taped. One finger of the surgical glove was temporarily closed with Kelly clamps in 3-instrument SLC. An additional 5-mm port was required during 4-instrument fundal retraction SLC (Fig. 1). Both a wound retractor and glove (with trocars) were inserted through a single port. Carbon dioxide gas was insufflated into a 12$\mathrm{mm}$ trocar with $15 \mathrm{~mm} \mathrm{Hg}$ of intra-abdominal pressure. A $30^{\circ}$ rigid 5-mm telescope (with a right angle light cable connector) and standard straight laparoscopic instruments were used (Fig. 1A). After inserting the laparoscopic instruments and telescope into the abdominal cavity, the trocars were retrieved from the fascia to create additional space and to increase the instruments' range of motion. Straight laparoscopic grasping instruments were applied while antegrade dissections were performed with two laparoscopic instruments in the 3-instrument group (Fig. 1B). We applied 4-instrument fundal retraction SLC using an additional straight laparoscopic grasping instrument for fundal retraction through the single port in the difficult cases to expose Calot's triangle (Fig. 1C). The additional instrument was attached on the operation drape using the Kelly clamp (Fig. 1A, indicator H). In cases of severe gallbladder distention or gallbladder wall thickening, 

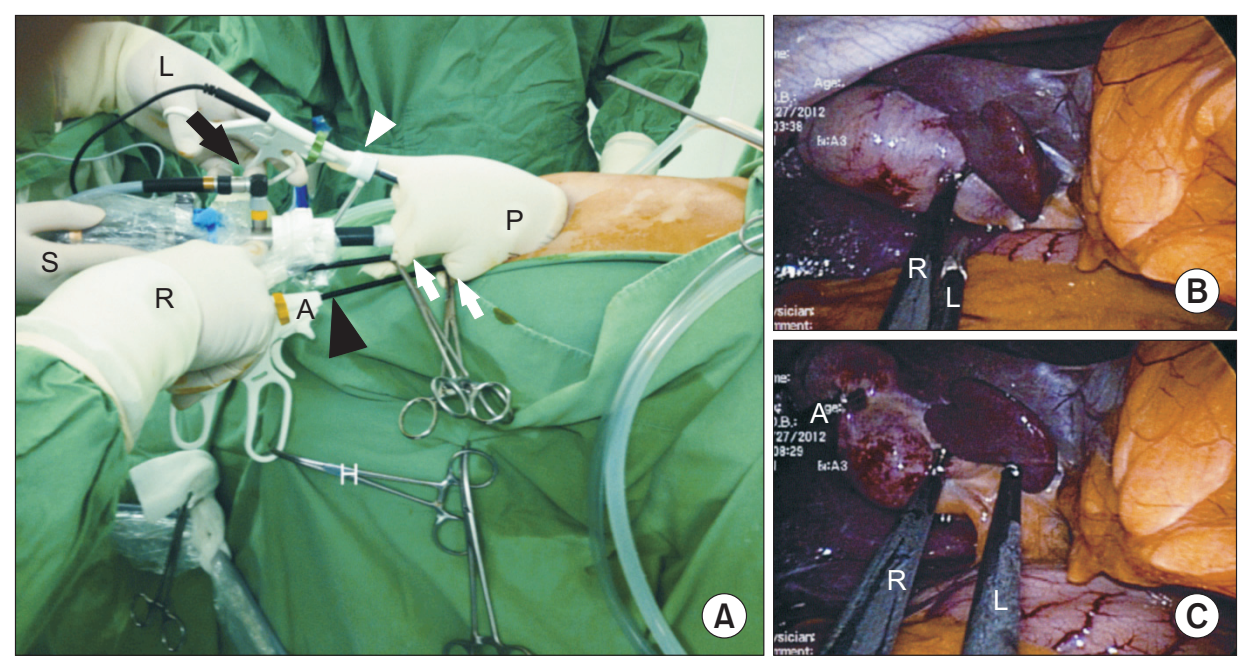

Fig. 1. External and internal views of a singleport laparoscopic cholecystectomy with simple fundal retraction. (A) Surgical field showing the placement of a handmade single port (P), additional instrument (A, black arrowhead) attached to an operation drape using Kelly clamps (H), the right hand (R) and the left hand (L) locations of the operator, assistant (S), the reduced number of ports (white arrow), small-sized head port (white arrowhead), and a $90^{\circ}$ bent-light cable connector (black arrow). (B) Intraoperative view showing the location of instruments during single-port laparoscopic cholecystectomy without simple fundal retraction. This figure shows difficulties in obtaining a clear view of Calot's triangle. (C) Intraoperative view shows the location of instruments during single-port laparoscopic cholecystectomy with simple fundal retraction. This figure displays a clearer view of Calot's triangle when retracting the gallbladder upwards and laterally.

gallbladder was retracted and elevated by mouth-open 4th instrument effectively without decompression by needle aspiration.

The cystic duct and artery were ligated twice individually. After the gallbladder was freed from its bed, the gallbladder specimen was excised from the abdominal cavity in an endo-bag. After irrigation and hemostasis, the surgical glove containing the trocars, the wound retractor and the endobag (containing the specimen) were removed. The vertical transumbilical incision was closed in layers.

\section{Statistical analysis}

Data are expressed as the mean \pm standard deviation for continuous variables. Statistical calculations were performed using IBM SPSS Statistics 20 software (Armonk, NY). For categorical variables, comparisons between groups were tested using the Pearson chi-square test. The independent sample $t$ test was used to compare continuous variables for the two groups. Univariate and multivariate logistic regression analyses were used to determine the effect ofrisk factors on the application of 4-instrument fundal retraction SLC. For multivariate analysis, variables were selected based on the univariate analysis results $(p<0.1) . p<0.05$ was considered statistically significant.

\section{RESULTS}

\section{Patient demographics}

Of 134 patients, 47 were male and 87 were female. The mean age of the patients was $42.4 \pm 12.7$ years. The mean BMI was $23.7 \pm 3.3 \mathrm{~kg} / \mathrm{m}^{2}$. Twenty-five patients $(18.7 \%)$ had $\mathrm{co}^{-}$ morbidities, including hypertension $(\mathrm{n}=9)$, diabetes mellitus $(n=4)$, chronic hepatitis $B(n=3)$, asthma $(n=2)$, coronary artery disease $(\mathrm{n}=2)$, a history of pulmonary tuberculosis $(n=2)$, a history of malignancy $(n=3)$, or chronic obstructive pulmonary disease $(n=1)$. Two patients had situs inversus totalis, one of whom was reported in a case presentation. ${ }^{10}$ Four patients (3.0\%) underwent a preoperative endoscopic retrograde cholangiopancreatographic (ERCP) procedure for the removal of common bile duct stones. Eight patients underwent a concurrent operation (6.0\%), including single port laparoscopic appendectomy $(\mathrm{n}=2)$, vaginal hysterectomy $(\mathrm{n}=1)$, right hemicolectomy $(\mathrm{n}=1)$, distal pancreatectomy $(\mathrm{n}=1)$, or video-assisted thoracic surgery lung wedge resection $(\mathrm{n}=1)$. Twelve patients (8.9\%) were converted to CLC. Pathologic reports revealed cholelithiasis ( $\mathrm{n}=101)$, cholesterol polyps $(n=20)$, gallbladder adenoma $(n=1)$, cholesterolosis $(n=28)$, acute cholecystitis $(n=12)$, or chronic cholecystitis $(n=130)$. Several patients had two or more findings on their respective pathologic reports. 


\section{Comparisons of the clinical characteristics between the 4-intrument fundal retraction SLC group and the 3-instrument SLC group}

There was no significant difference in the male-to-female ratio, or average age of patients in the two groups. The mean BMI was significantly higher in the 4-instrument fundal retraction group than the 3 -instrument group $(25.0 \pm 3.9$ versus $23.3 \pm 3.0 \mathrm{~kg} / \mathrm{m}^{2}, p=0.012$ ). The mean operation time (from skin incision to skin closure) was $74 \pm 23$ minutes. The mean operation time in the 4-instrument fundal retraction group (75 \pm 24 minutes) was not statistically different from that in the 3-instrument SLC group ( $72 \pm 16$ minutes) ( $p>0.05)$. A significantly higher proportion of the patients demonstrated gallbladder distention $(\mathrm{n}=13,40.6 \%)$ and wall thickening $(\mathrm{n}=17,53.1 \%)$ in the 4-instrument fundal retraction SLC group than that in the 3-instrument SLC group ( $\mathrm{n}=16,15.7 \%$, $p=0.003$ and $\mathrm{n}=24,23.5 \%, p=0.002$, respectively). However, the incidence of pericholecystic inflammation $(n=10,31.3 \%$ versus $\mathrm{n}=26.5 \%, p=0.598)$ and adhesions $(\mathrm{n}=14,43.8 \%$ versus $\mathrm{n}=28,27.5 \%, p=0.083)$ were not significantly different between the 4-instrument and 3-instrument groups. Gallbladder perforation occurred more frequently in the 4-instrument fundal retraction SLC group $(n=9,28.1 \%)$ than in the 3 -instrument SLC group ( $\mathrm{n}=18,17.6 \%)$, although this result was not statistically significant $(p=0.197)$.

Conversion to CLC occurred in 12 cases (9.0\%). Critical view of safety was disturbed by liver and surrounding structures in five cases (two cases in the 4-instrument and three cases in the 3-instrument SLC group). Acute cholecystitis with

Table 1. Comparisons of clinical outcomes between fundal retraction (4-instrument) and no fundal retraction (3-instrument) group in SLC

\begin{tabular}{|c|c|c|c|}
\hline & $\begin{array}{l}\text { 4-instrument (fundal retraction) } \\
\qquad(\mathrm{n}=32)\end{array}$ & $\begin{array}{l}\text { 3-instrument (no fundal retraction) } \\
\qquad(\mathrm{n}=102)\end{array}$ & $p$ value \\
\hline Gender (male:female ratio) & 1:2.56 & 1:1.68 & 0.345 \\
\hline Age (mean $\pm S D$, years old $)$ & $42.2 \pm 11.4$ & $43.0 \pm 16.3$ & 0.797 \\
\hline Body mass index $\left(\right.$ mean $\left.\pm S D, \mathrm{~kg} / \mathrm{m}^{2}\right)$ & $25.0 \pm 3.9$ & $23.3 \pm 3.0$ & $0.012^{*}$ \\
\hline Operation time (mean $\pm S D$, minutes) & $74.9 \pm 24.2$ & $72.3 \pm 16.4$ & 0.487 \\
\hline Preoperative ERCP & $2(6.3 \%)$ & $2(2.0 \%)$ & 0.241 \\
\hline \multicolumn{4}{|l|}{ Intraoperative findings } \\
\hline Gallbladder distention (n) & $13(40.6 \%)$ & $16(15.7 \%)$ & $0.003^{*}$ \\
\hline Gallbladder wall thickening (n) & $17(53.1 \%)$ & $24(23.5 \%)$ & $0.002^{*}$ \\
\hline Pericholecystic inflammation (n) & $10(31.3 \%)$ & $27(26.5 \%)$ & 0.598 \\
\hline Pericholecystic adhesions (n) & $14(43.8 \%)$ & $28(27.5 \%)$ & 0.083 \\
\hline Gallbladder perforation (n) & $9(28.1 \%)$ & $18(17.6 \%)$ & 0.197 \\
\hline Critical view of safety & $31(96.9 \%)$ & $102(100 \%)$ & 0.239 \\
\hline Presence of co-operation & $4(12.5 \%)$ & $4(3.9 \%)$ & 0.074 \\
\hline Conversion to conventional LC & $4(12.5 \%)$ & $8(7.8 \%)$ & 0.421 \\
\hline Complications (n) & $2(6.3 \%)$ & $8(7.8 \%)$ & 0.733 \\
\hline Postoperative hospital stay (mean $\pm S D$, days) & $2.0 \pm 1.0$ & $2.2 \pm 2.0$ & 0.666 \\
\hline \multicolumn{4}{|l|}{ Pathologic Results } \\
\hline Cholelithiasis & $27(84.4 \%)$ & $74(72.5 \%)$ & 0.176 \\
\hline Cholesterol polyp & $3(9.4 \%)$ & 17 (16.7\%) & 0.241 \\
\hline Cholesterolosis & $4(12.5 \%)$ & $24(23.5 \%)$ & 0.220 \\
\hline Adenoma & $1(3.1 \%)$ & 0 & 0.239 \\
\hline Chronic cholecystitis & $31(96.9 \%)$ & $99(97.1 \%)$ & 0.957 \\
\hline Acute cholecystitis & $1(3.1 \%)$ & $11(10.8 \%)$ & 0.292 \\
\hline
\end{tabular}

$S D=$ Standard deviation; ERCP $=$ Endoscopic retrograde cholangiopancreatogram; $L C=$ Laparoscopic cholecystectomy. ${ }^{*}$ Statistically significant. 
gallbladder wall thickening and distention were presented in seven cases, which did not guarantee the critical view of safety (two cases in the 4-instrument and five cases in the 3-instrument SLC group).

Complications occurred in 10 patients (7.5\%), including surgical site infection $(n=5)$ and postoperative wound pain $(n=5)$. All surgical site infections were all superficial and were treated conservatively. Two patients were admitted owing to postoperative wound pain, and three were successfully managed with oral pain medication in an outpatient setting. There was no statistical difference in the incidence of postoperative complications between the two groups. Comorbidities, or the incidences of preoperative ERCP procedures or a concurrent operation during cholecystectomy were not significantly different between the two groups. Finally, the mean duration of the postoperative hospital stay was not significantly different between the two groups (2.2 2.0 versus $2.0 \pm 1.0$ days, $p=0.67$ ) (Table 1).

\section{The logistic regression analyses of perioperative factors of 4-instrument fundal retraction SLC}

Higher BMI significantly increased the likelihood of 4-instrumentfundal retraction SLC (odds ratio (OR), 1.161; 95\% confidence interval (CI), 1.029-1.309; $p=0.015$ ). High BMI was also associated with a significant increase in operation time (OR, 1.268; 95\% CI, 1.117 1.438; $p<0.001$ ). Fourinstrument fundal retraction SLC was also commonly required for cases with gallbladder distention (OR 3.678; 95\% CI, 1.518 8.907; $p=0.004)$ and wall thickening (OR 3.683; 95\% CI, 1.604 8.460; $p=0.002)$ significantly. Although 4-instrument fundal retraction SLC was also frequently used in cases that developed pericholecystic inflammation, adhesions, and gallbladder perforation, no statistical significance between these complications and the 4-instrucment technique was noted. Age and gender did not increase the likelihood of 4-instrument fundal retraction SLC. In the multivariate analysis, gallbladder distention (OR, 3.000; 95\% CI, 1.114 8.084; $p=0.030)$ and the presence of concurrent operations during SLC (OR, 8.071; 95\% CI, 1.678 38.817; $p=0.009$ ) were independently significant factors (Table 2).

\section{DISCUSSION}

In the current study, we applied 4-instrument fundal retraction SLC in the difficult cases of benign gallbladder disease. This simple technique ensures the operation is less complicated in cases with high BMI, gallbladder distension and wall thickening. In SLC, obtaining a safe and unobstructed view of the critical area is difficult because of the lack of triangulation,

Table 2. The analysis for perioperative factors to converting 3-instrument to 4-instrument for simple fundal retraction

\begin{tabular}{|c|c|c|c|c|c|c|c|c|c|c|}
\hline \multirow[b]{3}{*}{ Age } & \multicolumn{5}{|c|}{ Univariate analysis } & \multicolumn{5}{|c|}{ Multivariate analysis } \\
\hline & \multirow{2}{*}{$\begin{array}{c}\text { B } \\
0.005\end{array}$} & \multirow{2}{*}{$\begin{array}{c}\text { OR } \\
1.005\end{array}$} & \multirow{2}{*}{$\begin{array}{c}p \text { value } \\
0.754\end{array}$} & \multicolumn{2}{|c|}{$95 \% \mathrm{Cl}$} & \multirow[t]{2}{*}{ B } & \multirow[t]{2}{*}{$\mathrm{OR}$} & \multirow[t]{2}{*}{$p$ value } & \multicolumn{2}{|c|}{$95 \% \mathrm{Cl}$} \\
\hline & & & & 0.974 & 1.037 & & & & & \\
\hline Gender & 0.417 & 1.517 & 0.347 & 0.636 & 3.618 & & & & & \\
\hline BMI & 0.149 & 1.161 & $0.015^{*}$ & 1.029 & 1.309 & 0.108 & 1.114 & 0.112 & 0.975 & 1.272 \\
\hline Preoperative ERCP & 0.773 & 2.167 & 0.531 & 0.192 & 24.388 & & & & & \\
\hline \multicolumn{11}{|l|}{ Intraoperative findings } \\
\hline Gallbladder distention & 1.302 & 3.678 & $0.004^{*}$ & 1.518 & 8.907 & 1.099 & 3.000 & $0.030^{*}$ & 1.114 & 8.084 \\
\hline Gallbladder wall thickening & 1.304 & 3.683 & $0.002^{*}$ & 1.604 & 8.460 & 0.921 & 2.512 & 0.062 & 0.995 & 6.604 \\
\hline Pericholecystic inflammation & 0.233 & 1.263 & 0.598 & 0.530 & 3.006 & & & & & \\
\hline Pericholecystic adhesions & 0.721 & 2.056 & 0.086 & 0.903 & 4.680 & 0.469 & 1.598 & 0.327 & 0.626 & 4.079 \\
\hline Gallbladder perforation & 1.178 & 3.247 & 0.062 & 0.942 & 11.186 & 0.476 & 1.610 & 0.381 & 0.554 & 4.676 \\
\hline Presence of cooperation & 1.253 & 3.500 & 0.090 & 0.823 & 14.893 & 2.088 & 8.071 & $0.009^{*}$ & 1.678 & 38.817 \\
\hline \multicolumn{11}{|l|}{ Pathologic results } \\
\hline Acute cholecystitis & -1.32 & 0.267 & 0.215 & 0.033 & 2.152 & & & & & \\
\hline Cholelithiasis & 0.715 & 2.043 & 0.182 & 0.716 & 5.831 & & & & & \\
\hline
\end{tabular}

$\mathrm{OR}=$ Odds ratio; $\mathrm{Cl}=$ Confidence interval; $\mathrm{BMI}=$ Body mass index $\left(\mathrm{kg} / \mathrm{m}^{2}\right) ; \mathrm{ERCP}=$ Endoscopic retrograde cholangiopanreatogram; $\mathrm{LC}=$ Laparoscopic cholecystectomy. ${ }^{*}$ Statistically significant. 
the collision of instruments, handling articulating laparoscopic instruments, crossed arms, crossed laparoscopic instruments, and awkward surgeon positioning. ${ }^{11}$ Our previous study on SLC showed that the Calot's triangle was poorly visible in $34 \%$ cases. ${ }^{12}$ The newly inserted instrument for fundal retraction functioned like a lever, and the single port worked like a fulcrum. As the ends of the instruments that grasped and retracted the gallbladder fundus were far from Calot's triangle, the additional instrument's handle remained away from the other instruments and the telescope. Although the additional instrument slightly reduced the working space within the single port, fundal retraction guaranteed a superior operative view and did not require additional percutaneous sutures or a mini-grasper in difficult cases.

Of the nine randomized controlled trials comparing SLC with CLC included in a meta-analysis, seven studies involved SLC with percutaneous gallbladder retraction. ${ }^{13}$ SLC without percutaneous sutures or mini-grasper were not common. A systematic review of 49 studies, including 7 randomized controlled and 11 case-matched trials, revealed 26 articles describing the routine or selective use of percutaneous sutures or other methods of retraction to improve visualization of Calot's triangle. ${ }^{14}$ These methods frequently caused intraoperative bile spillage and reduced the mobilization of Hartmann's pouch during dissection. However, additional gallbladder retraction that included percutaneous sutures and intracorporeal devices enhanced the rate of SLC completion in difficult cases. Many technical reports documenting gallbladder retraction during SLC ${ }^{15-18}$ indicate that technical difficulties were encountered frequently. Furthermore, the use of percutaneous sutures and mini-graspers instead of traditional assistance ports was feasible in SLC. ${ }^{19}$ Our uncomplicated fundal retraction, with one additional instrument, offers a useful replacement for percutaneous sutures or minigraspers in difficult SLC cases.

Several studies have reported that patients with high BMIs can be treated successfully with SLC. ${ }^{20,21}$ However, the conversion rate in obese patients was significantly high. ${ }^{21,22}$ Considering the significantly higher BMI in the 4-instrument fundal retraction SLC group compared to that in the 3-instrument SLC group (without a significant difference in operation time), we carefully concluded simple fundal retraction can expand the clinical indications for SLC in patients with higher BMIs.

A review of published literature concluded that acute cholecystitis is not a contraindication to SLC. ${ }^{23,24}$ However, SLC in patients acute inflamed gallbladder cases demands a longer operative time and a higher rate of additional trocars. ${ }^{24}$ In addition, bile duct injury can be avoided if the gallbladder is gripped at the infundibulum and dissected at the infundibulum-cystic duct junction rather than at the cystic duct-common bile duct junction. ${ }^{25}$ As infundibular retraction is limited owing to technical restrictions in SLC, gallbladder wall thickening or distention can impact patient safety by critically obstructing the view during the procedure. Our study offers a simple gallbladder fundal retraction utilizing an additional instrument through the same single port. Therefore, we suggest that clinical indications of 4-instrument fundal retraction SLC are based on cases in which obtaining an optimal surgical view is difficult, thus impacting patient safety. These indications include a high patient BMI, the view of Calot's triangle obstructed by the liver, gallbladder buried in the liver, pericholecystic adhesion, inflammation around the cystic duct, gallbladder wall thickening or distention, or abnormal anatomical position of the gallbladder.

Our study is limited as the obtained data originates from a single surgeon's clinical experience with a non-randomized cohort. As patients were allocated to study groups based on both operative circumstances and a single surgeon's decision, we cannot exclude a selection bias.

To reduce "conflict" among surgical instruments, the introduction of a traction instrument may be necessary. Reducing instrument "conflict" will decrease operative time and widen the clinical indications for single-port laparoscopic surgery in the future.

\section{CONCLUSION}

Based on the results of this retrospective study, we can conclude that 4-instrument fundal retraction SLC is feasible in patients with difficulties, included a higher BMI, distended gallbladder, or gallbladder wall thickening. Importantly, in the clinical practice, case difficulty is subject to a surgeon's discretion. When difficulties are encountered during a 3 -instrument SLC, simple fundal retraction, with an additional instrument, is the preferred option prior to converting to CLC.

\section{ACKNOWLEDGEMENTS}

This work was supported by the research seed fund from the Korea University Research and Business Foundation.

\section{REFERENCES}

1) Brown KM, Moore BT, Sorensen GB, et al. Patient-reported outcomes after single-incision versus traditional laparoscopic cholecystectomy: a randomized prospective trial. Surg Endosc 2013;27:3108-3115.

2) Aprea G, Coppola Bottazzi E, Guida F, Masone S, Persico G. Laparoendoscopic single site (LESS) versus classic video- 
laparoscopic cholecystectomy: a randomized prospective study. J Surg Res 2011;166:e109-112.

3) Ma J, Cassera MA, Spaun GO, Hammill CW, Hansen PD, Aliabadi-Wahle S. Randomized controlled trial comparing singleport laparoscopic cholecystectomy and four-port laparoscopic cholecystectomy. Ann Surg 2011;254:22-27.

4) Marks J, Tacchino R, Roberts $K$, et al. Prospective randomized controlled trial of traditional laparoscopic cholecystectomy versus single-incision laparoscopic cholecystectomy: report of preliminary data. Am J Surg 2011;201:369-372; discussion 372-363.

5) Lirici MM, Califano AD, Angelini P, Corcione F. Laparo-endoscopic single site cholecystectomy versus standard laparoscopic cholecystectomy: results of a pilot randomized trial. Am J Surg 2011;202:45-52.

6) Jacob DA, Raakow R. Single-port transumbilical endoscopic cholecystectomy: a new standard? Dtsch Med Wochenschr 2010; 135:1363-1367.

7) Ostlie DJ, Juang OO, Iqbal CW, et al. Single incision versus standard 4-port laparoscopic cholecystectomy: a prospective randomized trial. J Pediatr Surg 2013;48:209-214.

8) Han HJ, Choi SB, Kim WB, Choi SY. Single-incision multiport laparoscopic cholecystectomy: things to overcome. Arch Surg 2011;146:68-73.

9) Podolsky ER, Curcillo PG, 2nd. Reduced-port surgery: preservation of the critical view in single-port-access cholecystectomy. Surg Endosc 2010;24:3038-3043.

10) Han HJ, Choi SB, Kim CY, Kim WB, Song TJ, Choi SY. Singleincision multiport laparoscopic cholecystectomy for a patient with situs inversus totalis: report of a case. Surg Today 2011;41:877880.

11) Antoniou SA, Pointner R, Granderath FA. Single-incision laparoscopic cholecystectomy: a systematic review. Surg Endosc 2011; 25:367-377.

12) Han HJ, Choi SB, Park MS, et al. Learning curve of single port laparoscopic cholecystectomy determined using the non-linear ordinary least squares method based on a non-linear regression model: An analysis of 150 consecutive patients. J Hepatobiliary Pancreat Sci 2011;18:510-515.

13) Wu XS, Shi LB, Gu J, et al. Single-incision laparoscopic cholecystectomy versus multi-incision laparoscopic cholecystectomy: a meta-analysis of randomized clinical trials. J Laparoendosc Adv
Surg Tech A 2013;23:183-191.

14) Hall TC, Dennison AR, Bilku DK, Metcalfe MS, Garcea G. Singleincision laparoscopic cholecystectomy: a systematic review. Arch Surg 2012;147:657-666.

15) Reibetanz J, Wierlemann A, Germer CT, Krajinovic K. A novel technique for fundal retraction of the gallbladder in single-port cholecystectomy. J Laparoendosc Adv Surg Tech A 2011;21:427429.

16) Rupp CC, Farrell TM, Meyer AA. Single incision laparoscopic cholecystectomy using a "two-port" technique is safe and feasible: experience in 101 consecutive patients. Am Surg 2011;77:916-921.

17) Choi SH, Hwang HK, Kang CM, Lee WJ. Single-fulcrum laparoscopic cholecystectomy: a single-incision and multi-port technique. ANZ J Surg 2012;82:529-534.

18) Sumiyoshi K, Sato N, Akagawa S, et al. Single-incision laparoscopic cholecystectomy with needle graspers. Hepatogastroenterology 2012;59:325-328.

19) Davila F, Tsin D, Gonzalez G, Davila MR, Lemus J, Davila U. Use of percutaneous needles in the feasability of single-port laparoscopic cholecystectomy. Cir Esp 2014;92:261-268.

20) Rivas H, Varela E, Scott D. Single-incision laparoscopic cholecystectomy: initial evaluation of a large series of patients. Surg Endosc 2010;24:1403-1412.

21) Roberts KE, Solomon D, Duffy AJ, Bell RL. Single-incision laparoscopic cholecystectomy: a surgeon's initial experience with 56 consecutive cases and a review of the literature. J Gastrointest Surg 2010;14:506-510.

22) Kamoun S, Alves A, Bretagnol F, Lefevre JH, Valleur P, Panis Y. Outcomes of laparoscopic colorectal surgery in obese and nonobese patients: a case-matched study of 180 patients. Am J Surg 2009;198: 450-455.

23) Jacob D, Raakow R. Single-port versus multi-port cholecystectomy for patients with acute cholecystitis: a retrospective comparative analysis. Hepatobiliary Pancreat Dis Int 2011;10:521-525.

24) Sasaki K, Watanabe G, Matsuda M, Hashimoto M. Original singleincision laparoscopic cholecystectomy for acute inflammation of the gallbladder. World J Gastroenterol 2012;18:944-951.

25) Kumar M, Agrawal CS, Gupta RK. Three-port versus standard four-port laparoscopic cholecystectomy: a randomized controlled clinical trial in a community-based teaching hospital in eastern Nepal. JSLS 2007;11:358-362. 